$\underline{\text { Auf }}{ }^{1}, \underline{\text { Selim }} \mathrm{M}^{2}, \underline{\text { Selim }} \mathrm{E}^{3}$

\title{
Prevalence of Amblyopia in 2018
}

${ }^{1}$ Associate professor, Department of Health, Human Performance, and leisure (HHPL), College of Arts and Science (COAS), Howard University, Washington, DC 20059, USA

${ }^{2}$ Jackson South Hospital, Palmetto Bay, FL 33157

${ }^{3}$ Retinal Unit, Eye Surgery Consultant, London, United Kingdom

Corresponding Author: Emad Selim, MD, FRCOphth

Address: Retinal Unit, Eye Surgery Consultant, 85 Great Portland street, London, W1W 7LT, United Kingdom.

Received date: 10 April 2019; Accepted date: 13 May 2019; Published date: 20 May 2019

Citation: Selim E, Selim M, Auf R, "Prevalence of Amblyopia in 2018”. Asp Biomed Clin Case Rep, vol.2, no.1: 18$20,2019$.

Copyright (C) 2019 Selim E, Selim M, Auf R, This is an open access article distributed under the Creative Commons Attribution License, which permits unrestricted use, distribution, and reproduction in any medium, provided the original work is properly cited.

\section{Abstract}

Purpose: Amblyopia is a leading cause of preventable visual impairment which can have consequences on psychosocial wellbeing. This study aims to find out the prevalence of amblyopia reported in 2018.

Methods: Pubmed was searched for amblyopia prevalence. Relevant articles were reviewed.

Results: Amblyopia prevalence was reported as high as 17.2 of children screened in one study.

Discussions: Prevalence rate of amblyopia can vary significantly between countries as well as certain communities in the same country.

\section{Keywords}

Amblyopia; Visual; Impairment; Preventable; Prevalence

\section{Introduction}

Amblyopia is a leading cause of visual impairment. Literally, amblyopia means dull vision when the eye sight in one or both eyes is less than what is expected of an eye with normal morphology [1]. The condition normally starts in childhood and if not treated promptly it will be harder to treat as the child gets older and hence continues into adulthood [2]. Children with family history of strabismus and high refractive errors are at increased risk of developing amblyopia. It is essential to estimate the prevalence of amblyopia around the world in order to highlight the significance of a preventable cause of visual impairment.

\section{Method}

Authors used searched Pubmed for amblyopia prevalence limiting results to the year 2018. The search returned 53 records. All abstracts were in English language. Only fifty-one articles were in English. After reviewing abstracts of the fifty-one remaining records, 16 articles were found relevant. The sixteen articles were reviewed for prevalence among countries studied.

\section{Results}

The sixteen articles depicted research conducted by 11 countries and reported prevalence in 12 countries. Most articles were from Iran which produced a total of four articles in the year 2018. One of the articles reported a global prevalence of amblyopia of $1.75 \%$. 

2019 .

The other articles reported a rate between $6.9 \%$ and $14.5 \%$. Iran was followed on the list of higher reporting countries equally by India and Denmark. Each of them produced two articles. India reported rates of $1.75 \%$ and $17.2 \%$. Denmark on the other side reported rates of $1.5 \%$ and $2.7 \%$. Egypt also produced two articles. However, one of them reported the amblyopia rate among Egyptians in the range of $1.98 \%$ while the other article reported amblyopia among Yemeni children to $6.7 \%$. The rest of countries on the list included; Saudi Arabia 2.5\%, China 1.47\%, Romania 2.8\%, Bulgaria 2.5\%, Malaysia 7.53\%, Israel $1.2 \%$ to $0.8 \%$ and Brazil $0.81 \%$.

\section{Discussion}

The prevalence of amblyopia was found to be highest among European and lowest among African populations as depicted by Hashemi et al [3]. Our results agree with Hashemi et al's in respect to African population as shown by the Egyptian report of a rate of $1.98 \%$, very consistent with the world-wide rate of 1.75\% [4], however not one of the lowest. Denmark [5], Saudi Arabia [6], China [7], Romania [8], Bulgaria [9], Israel [10] and Brazil [11] reported rates ranging around the average rate worldwide. Although the reporting countries varied between Asian, European, South American and Middle Eastern, the results did not very much. However, other Asian countries like Malaysia [12], Iran [13,14], and India [15],which reported the highest prevalence rates in tribal children, have substantially higher rates than reported elsewhere.

\section{Conclusion}

The notion that European population has the highest prevalence rates of amblyopia might not be true according to reports from around the world in 2018. Authors found no reason to believe that a certain race would have more amblyopia prevalence than the other. The higher prevalence rate in Europe is previously thought could be due to more screening for the condition.

\section{Conflict of interest}

Authors declare no conflict of interest.

\section{References}

[1] Ikuomenisan SJ, Musa KO, Aribaba OT, et al., "Prevalence and pattern of amblyopia among primary school pupils in Kosofe town, Lagos state, Nigeria”. Niger Postgrad Med J, vol.23, no.4: 196-201, 2016.

[2] Mojon-Azzi SM, Mojon DS, "Opinion of headhunters about the ability of strabismic subjects to obtain employment”. Ophthalmologica, vol.221, no.6: 430-33, 2007.

[3] Hashemi H MD, Pakzad R MSc, Yekta A PhD, et al., "Global and regional estimates of prevalence of amblyopia: A systematic review and metaanalysis". Strabismus, vol.26, no.4: 2018.

[4] Rashad MA, Abd Elaziz KM, Fawzy SM, et al., "Screening of Primary School Children for Amblyopia and Amblyogenic Factors in Central Cairo, Egypt".J Ophthalmol, vol.2018: 2018.

[5] Hansen MH, Munch IC, Li XQ, et al., "Visual acuity and amblyopia prevalence in 11- to 12-year-old Danish children from the Copenhagen Child Cohort 2000". Acta Ophthalmol, vol.97, no.1: 29-35, 2019.

[6] Alsaqr A, Abu Sharha A, Fagehi R, et al., "The visual status of adolescents in Riyadh, Saudi Arabia: a population study". Clin Ophthalmol, vol.12: 965-72, 2018.

[7] Huang D, Chen X, Zhu H, et al., "Prevalence of amblyopia and its association with refraction in Chinese preschool children aged 36-48 months". Br J Ophthalmol, vol.102, no.6: 767-71, 2018.

[8] Mocanu V, Horhat R, "Prevalence and Risk Factors of Amblyopia among Refractive Errors in an Eastern European Population”. Medicina (Kaunas), vol.54, no.1: 6, 2018.

[9] Dikova SP, Dragoev SA, Chernodrinska VS, "Prevalence of amblyopia in Bulgaria". Strabismus, vol.26, no.4: 163-67, 2018.

[10] Shapira Y, Machluf Y, Mimouni M, et al., "Amblyopia and strabismus: trends in prevalence and risk factors among youngadults in Israel”. $\mathrm{Br} \mathrm{J}$ Ophthalmol, vol.102, no.5: 659-66, 2018.

[11] Schaal LF, Schellini SA, Pesci LT, "The Prevalence of Strabismus and Associated Risk Factors in a Southeastern Region of Brazil”. Semin Ophthalmol, vol.33, no.3: 357-6o, 2018.

[12] Chew FLM, Thavaratnam LK, Shukor INC, et al., "Visual impairment and amblyopia in Malaysian preschool children - The SEGPAEDS study". Med J Malaysia, vol.73, no.1: 25-30, 2018.

[13] Akbarzadeh S, Vahabi R, Bazzazi N, et al., "The burden of pure anisometropic amblyopia: a crosssectional study on 2800 Iranians". Int Ophthalmol, vol.38, no.1: 29-34, 2018.

[14] Ghaderi S, Hashemi H, Jafarzadehpur E,et al., 

2019 .

\section{Short Communication}

"The prevalence and causes of visual impairment in seven-year-old children”. Clin Exp Optom, vol.101, no.3: 380-85, 2018.

[15] Magdalene D, Bhattacharjee H, Choudhury M, et al., "Community outreach: An indicator for assessment of prevalence of amblyopia”. Indian $J$ Ophthalmol, vol.66, no.7: 940-44, 2018. 